Sains Malaysiana 48(9)(2019): 2029-2039

http://dx.doi.org/10.17576/jsm-2019-4809-24

\title{
Atomistic Simulations of Nanoindentation Response of Irradiation Defects in Iron
}

(Simulasi Atomistik bagi Tindak Balas Pelekukan Nano bagi Kecacatan Penyinaran dalam Besi)

\author{
M. Mustafa AZEEM, QINGYU WANG* \& MUHAMMAD ZUBAIR
}

\section{ABSTRACT}

Radiation response of a material is a consequence of defects' evolution in any radiation damage event. The radiationinduced defects can significantly alter the mechanical properties of a material. Radiation damage initiates from incident neutron by bombardment on solid material causing production and evolution of Frenkel defects. Since voids are formed due to aggregation of a large number of vacancies that cause dimensional changes and hence irradiation-induced swelling. In order to characterize the effect of irradiation defects, we have performed molecular dynamics (MD) simulations to investigate nanoindentation response of point defects and voids in Fe and their effects on mechanical parameters. The radial effect of voids and their interaction mechanism is also explored by nanoindentation simulation. It has been found that most of the dislocation produced are $\frac{1}{2}\langle 111\rangle$ and $\langle 100\rangle$ during nanoindentation in all simulated models. There will be an increase in dislocation density which will harden the material and reduce its toughness. The mechanical parameters such as hardness $H$ and reduced elastic modulus $E_{r}$ of irradiation defects are calculated from $P$ - $h$ curves. It is found that both $H \& E_{r}$ of the point defects and voids are lower than the perfect model.

Keywords: Elastic modulus; hardness; irradiation defects; molecular dynamics simulations; nanoindentation

\section{ABSTRAK}

Tindak balas sinaran sesuatu bahan adalah kesan daripada evolusi kecacatan dalam kejadian kerosakan sinaran. Punca kecacatan aruhan sinaran dengan ketara boleh mengubah sifat mekanik bahan. Kecacatan sinaran yang dimulakan daripada kejadian neutron dengan pembedilan pada bahan pepejal menyebabkan pengeluaran dan evolusi kecacatan Frenkel. Lompang terbentuk kerana pengagregatan sebilangan besar kekosongan yang menyebabkan perubahan dimensi dan bengkak teraruh penyinaran. Untuk mencirikan kesan kecacatan penyinaran, simulasi molekul dinamik (MD) telah dijalankan untuk mengkaji tindak balas pelekukan nano kecacatan titik dan lompang pada Fe dan kesannya terhadap parameter mekanik. Kesan jejari lompang dan mekanisme interaksinya juga diterokai oleh simulasi pelekukan nano. Didapati bahawa kebanyakan kehelan yang dihasilkan adalah $\frac{1}{2}<111>$ dan $<100>$ semasa pelekukan-nano dalam semиa model simulasi. Terdapat peningkatan dalam ketumpatan perkehelan yang akan mengeraskan bahan dan mengurangkan keliatan. Parameter mekanik seperti kekerasan H dan pengurangan sinaran kecacatan modulus elastik $E_{r}$ akan dihitung bermula dari lengkung $P$-h. Didapati bahawa kedua-dua titik cacat dan lompang $H$ \& Er adalah lebih rendah berbanding model yang sempurna.

Kata kunci: Kecacatan sinaran; kekerasan; modulus elastik; pelekukan nano; simulasi molekul dinamik

\section{INTRODUCTION}

Radiation damage (RD) is a critical and challenging phenomena to be catered in structural materials of advanced reactors (Azevedo 2011). Radiation-induced microstructural evolution leads to swelling, irradiation growth and hence, changes in mechanical properties (Zinkle \& Was 2013). In nuclear power industry, Fe-based alloys are extensively used as structural and cladding materials due to their excellent mechanical strength (Tan et al. 2016; Yvon \& Carré 2009). Ferritic alloys have excellent void swelling resistance under ion irradiation (Yabuuchi et al. 2013). Long-term irradiation and high temperatures may cause extended defects like voids in the interior of the material that can change microstructure. Irradiation swelling depends on dislocation density and size of voids and precipitates (Renault et al. 2015). Voids and dislocation loops are sources of void swelling and dimensional instabilities in the material (Bacon et al. 1994). Voids and bubbles are in the form of 3D vacancy clusters. Voids are vacancies which are independent of internal stresses while cavities are pressurized vacancies.

Nanoindentation also known as depth-sensitive technique (Ruestes 2017). It is one of the simplest and perhaps most common method for testing the mechanical properties of materials (Christopher et al. 2001). Prismatic dislocation loops are formed in metals after nanoindentation as seen by atomistic studies in BCC metals (Dalmau et al. 2012). Atomistic simulations can depict detailed insights into the physical and chemical phenomena to validate experimental results at the nanoscale (Uberuaga et al. 2018).

Nanoindentation performed by Richter et al. (2008) showed that hardness was increased in the presence of 
clusters and voids for $\mathrm{MgO}$. Classical molecular dynamics (MD) simulation of nanoindentation performed by Kilymis et al. (2016) on glass material showed that hardness is decreased after irradiation. Du et al. (2015) performed MD simulation of nanoindentation for silicon. The result showed that phase transformation was observed with increasing temperatures and strengthened anisotropy at low temperatures. Atomistic simulation performed on monocrystal $\mathrm{Cu}$ by Shan et al. (2009) demonstrated that the size of void and position of indenter affects the nucleation of dislocations. Lee et al. (2005) studied nanoindentation response of $\mathrm{Al}$ and found that nucleation of dislocation loops is dependent on position of indenter. Voyiadjis and Yaghoobi (2015) observed that size and speed of indenter did not affect the nucleation of dislocations after certain depth. Tan and Jeng (2009) mentioned that voids have a significant influence on hardness in $\mathrm{Cu}(100)$. Cheong and Zhang (2006) performed MD simulation and showed that phase transformation was observed after nanoindentation in Si. Ruestes (2017) reviewed the latest developments in the atomistic simulation of nanoindentation. Most of the previous nanoindentation simulation studies have discussed and explained behavior of materials without voids or single void in different materials including Fe but none has considered nanoindentation response of multiple random spherical voids in the Fe.

For single-element crystals like $\mathrm{Fe}$ in our case, the basic form of point defects are vacancy and interstitial atoms (Nordlund et al. 2018). In any crystal, number of vacancies and interstitial atoms are more or less equal. At any temperature $\mathrm{T}$, the concentration of vacancy and interstitial atoms under thermal equilibrium can be calculated by equilibrium thermodynamics (Was 2007). Theoretically and experimentally, accurate calculations of these quantities are more complicated. In particular, interstitial atoms may have a variety of interstitial sites like octahedral and tetrahedral (Wolfer 2012). Assuming a simple estimate of the equilibrium concentration of vacancies and interstitials for Fe as $E_{i}^{F} \sim 4 \mathrm{eV}$ and $E_{v}^{F} \sim 1 \mathrm{eV}$ and $S_{i}^{F}=S_{i}^{F} \sim 0$ (Tschopp et al. 2014, 2011). Our calculation of equilibrium thermodynamic results are $C_{V} \approx 1.64 \times 10^{-17}$ and $C_{i} \approx 7.30 \times 10^{-68}$, where $S_{v}^{F}$ and $S_{i}^{F}$ are the formation entropies, while $E_{v}^{F}$, and $E_{i}^{F}$ are formation energies of vacancy and interstitial atom, respectively. Hence, thermal equilibrium interstitial concentration is far less than the thermal equilibrium concentration of vacancies and this is the reason for choosing point defects as voids instead of interstitials.

During irradiation, a large number of vacancies aggregate and grow in all three-dimensions leading to cavities within the metal which subsequently produce swelling (Nordlund et al. 2018). Eldrup and Singh (2013) found that neutron irradiation in Fe causes void swelling in range of 300-623 K. Rofman et al. (2017) observed that cavities in stainless steel after exposure to low doses of fast neutrons are non-homogeneous spherical facet with larger cavities at higher temperatures. Since cavities often appear in the shape of a regular octahedron on the (111) surface, the octahedral vertices are truncated by (110) planes (Kohnert et al. 2018). Formation of cavities at $723 \mathrm{~K}$ causes a higher level of degradation in mechanical properties (Yabuuchi et al. 2013). Post-irradiation annealing results in cavities formation is dependent on the microstructure evolution (García et al. 2016; Terentyev et al. 2013). Post-irradiation results in voids along with stacking fault tetrahedral (SFT) formation as secondary defects through accumulation of vacancies. The high concentration of vacancies tend to form SFT at lower temperatures while voids tend to form at higher temperatures (Zhang et al. 2018). Therefore, it is of great significance to study the effect of voids on the mechanical properties of Fe.

The main objective of this study was to simulate perfect, point defects, and spherical voids models and analyze their nanoindentation response through MD simulations. The obtained mechanical parameters such as hardness and elastic modulus have been calculated and analyzed for each model by P-h curve in relation to different sizes and positions of spherical voids. Since ion irradiation has been used as a surrogate source for studying void swelling in iron (Liu et al. 2017), we assumed that all simulated models are posterior to neutron irradiation.

In this study, we have focused on the initial deformation phase because our indentation depth is comparatively lower than the experimental values. This study comprises of mainly three parts: Development of the perfect single crystal and its nanoindentation response, analysis of irradiation defects by nanoindentation while creating point defect and multiple spherical voids, and interactions of point defects and spherical voids having dislocations and calculation for mechanical parameters such as hardness and elastic modulus. Our simulated models are relatively in agreement with the latest literature available in both experimental and simulation studies of nanoindentation.

\section{MATERIALS AND SimUlation MethodS}

In order to study nanoindentation response of irradiated $\mathrm{Fe}$, we considered a perfect 3D Fe crystal model having a lattice constant of $2.863 \AA$. The dimensions of the simulation cell are $171 \AA \times 171 \AA \times 114 \AA$, containing 291600 atoms. Figure 1 represents a schematic diagram prior to the indentation in a perfect model.

All MD simulations are performed by Large-scale Atomic/Molecular Massively Parallel Simulator (LAMMPS) (Plimpton 1995). Since the accuracy of MD simulations is dependent on the selection of suitable potential for a specific model. Therefore, the Embedded-Atom Method (EAM) interatomic potential for Fe, developed by Ackland et al. (2004) has been used to describe the interaction between $\mathrm{Fe}$ atoms. A repulsive force has been exerted on the interface between the indenter and the atoms.

The simulation of indentation consists of two steps for each model, initially an equilibrium stage and then the indentation stage. The model is thermally relaxed at first by NVT ensemble using the velocity Verlet algorithm at 


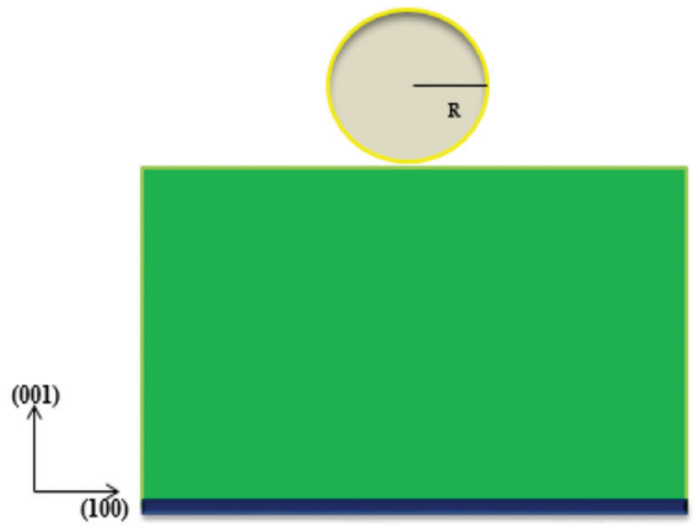

FIGURE 1. Schematic diagram of the indentation model having an indenter of radius R. The green part indicates Newtonian atoms and the blue color displays the fixed atoms boundary layer

$300 \mathrm{~K}$ with a time step of $0.001 \mathrm{ps}$ for $100 \mathrm{ps}$. In the next step, the model is relaxed again for another $100 \mathrm{ps}$ with the same time step and temperature using NVE ensemble. During this phase, we fixed a layer of $2 \AA$ underside atoms to act as a substrate to avoid any rigid body motion during indentation, as displayed in Figure 2. In our models we assumed $\mathrm{x}, \mathrm{y}$ directions are periodic while $\mathrm{z}$-direction is non-periodic.

Nanoindentation is performed by using NVE ensemble at $300 \mathrm{~K}$ with a spherical rigid virtual indenter of radius 43 $\AA$ placed exactly at the top-center of the simulation box. For our simulations, indenter with constant speed $\sim 0.001$ $\AA / p s$ having a time step of 0.005 ps and $20 \AA$ penetrating depth is set along the z-axis. As indentation speed in our case is higher as compared to the experimental values $\left(10^{-8}-10^{-11} \AA \mathrm{\AA} / \mathrm{ps}\right)$, we have set the speed slow enough so that the system remains nearly at equilibrium (Mazaheri et al. 2015). Our simulation parameters are comparable with Abu-shams and Ishraq (2017) and Shan et al. (2009). Nanoindentation simulation has been carried out by adjusting indenter's displacement. At each time step, the indenter is held fixed and minimization is attained for each new stable configuration until indenter reaches maximum depth, i.e. 20 Å. Relationship between indenter depth and load can be obtained from the movement of the indenter, perpendicular to the simulation box. Deformation speed is the same as it was in the unloading phase when indenter reaches maximum depth. Post-processing visualization and dislocations' evolution is identified by OVITO (Stukowski 2010). For each simulation case, the penetration depth of indenter and forces are calculated and plotted in the loaddisplacement curve at each time step during the movement of the indenter. Other simulation details for each simulated model is explained in the following section.

For point defects, models' selection criteria of different percentages for $\mathrm{Fe}$ is chosen, based on porosity for each model. This parameter was calculated based on the total number of atoms created by each model e.g. $1 \%$ atoms were randomly deleted to create $1 \%$ point defect model and so on. We have chosen selection parameter after several attempts. Finally, porosity was adjusted to 0.0105 as it was closest to $1 \%$ while achieving model stability. A similar approach was conducted for $2 \%, 3 \%$, and $4 \%$ vacancies. Since the probability of overlap is very low; therefore, it was assumed that vacancies did not overlap and thus void generation was avoided. Although the cavities are not spherical in experimental observations. As reported by Shan et al. (2009), we considered spherical approximation for all voids cases. In our simulation, we assumed two cases for voids model. For model A, we have considered that total number of deleted atoms are invariant while the number of spheres and their positions have been changed as shown in Figure 6. In this case, total numbers of deleted atoms are 1-2\% and radii of the spherical region are taken as 2, 3, 4 (where $\mathrm{R}=\mathrm{R} 1(2,3,4) \times$ L.c i.e.5.726, $8.589,11.452 \AA$ ). . For model B, we assumed that the total number of deleted atoms is changing while the number of spheres and their positions remain invariant as shown in Figure 8.

Furthermore, appropriate selection criterion for spherical region of the two models is crucial to avoid any uncertainty arising from overlapping of regions which may invariably effect P-h curve. The interference of such factors can be eliminated by considering three important conditions during structural modeling. Firstly, spherical areas that simulate each cavity should be independent of each other to avoid overlapping with other spherical areas. Secondly, the selected center of sphere should be random. Thirdly, the spherical area should be inside the simulation box, i.e. there should be no part of the spherical area that contains the boundaries of the model. Such situation may result in a reduction of deleted atoms.

Furthermore, it is worth mentioning that in point defects and void models, the structures have been stabilized with no expansion or contraction of models before indentation and no cracks were observed after the indentation process.

\section{RESULTS AND DISCUSSION}

\section{PERFECT MODEL}

Figure 2 displays the load-displacement curve. During first part of the p-h curve (before the yield point), first stable dislocation $1 / 2<\mathbf{1 1 1}>$ is nucleated at nearly $10 \AA$. After that there is a series of elastic-plastic phases due loading and unloading of indenter. This is caused by temporary defect formation during initial deformation phase. Meanwhile, the value of load continually drops with the increase in indentation depth. The moment P-h curve drops, critical point is reached. The value of load at this critical point is $\approx 590 \mathrm{nN}$ at $10 \AA$. Point 2 (c') in the figure, serves as a limit for maximum loading. A significant change takes place below the point where the indenter is located. The initial phase of the unloading part is elastic. However, later on, pop up events appear when the load is removed. In P-h curve, the relationship 
between the pressure $\mathrm{P}$ and the displacement $\mathrm{h}$ follows Hertz theory as reported by Tan and Jeng (2009) for single $\mathrm{Cu}$ crystal, having a void under the constant indenter pressure. It can be noted that the elastic phase before point 2(b') exhibits similar behavior reported by Zhan et al. (2011).

After the first major dislocation occurs, the model cannot be restored to its original shape. This is also consistent with the MD simulation results (Abu-shams \& Ishraq 2017; Shan et al. 2009). The second major dislocation nucleates at the maximum indenter depth $\approx 20$ $\AA$. Variation in the indenter pressure results in dislocations at 2(b'), 2(c') 2(d') with load values as $590,755,700 \mathrm{nN}$, respectively. Figure 3 shows a snapshot of deformation phases during nanoindentation. It can be vividly seen that, when pressure $\mathrm{P}$ has an abrupt reduction at $\sim 10.5$ $\AA$, dislocation nucleation of type $1 / 2<111>$ and $<100>$ occurs. A similar change occurs in pressure near $\sim 17.5$ $\AA$ and $20 \AA$ with dense dislocation segments and higher dislocation density under indenter tip as shown where yellow color represents $1 / 2<111>$ and pink color $<100>$ dislocation segments. The nucleation of dislocation and their movement further continues the multiplication effect until maximum indentation depth is reached.

\section{POINT DEFECTS MODEL}

Point defects are amongst the most basic and primary defects in the irradiated model. It is considered that the occurrence of point defects is random, since the lattice atoms in the actual $\mathrm{Fe}$ crystal collide randomly due to thermal vibration.

Figure 4(a)-4(d)) represents MD snapshot of 1-4\% randomly deleted atomic models, white part represents the deleted $\mathrm{Fe}$ atom while the blue layer at the bottom is fixed. Figure 5 compares P-h curves for point defect models with the perfect model. It can be observed that the trend of P-h curve for $1 \%$ atom model is similar to that of perfect model. It can be seen that maximum value of $\mathrm{P}$-h curve for $2 \%, 3 \%$ and $4 \%$ is shifted downward along the abscissa since more dislocations are generated as compared to the perfect model. Furthermore, we can see that the slopes of the point defect models are smaller than the perfect model. Hence, the elastic modulus decreases.

In the initial phase of nanoindentation, the model can be approximated as being elastic with critical load limit for each curve at $\approx 590,400,300,230,210 \mathrm{nN}$, respectively. It means that the existence of point defects aggravates brittleness. This shows that the mechanical properties of the model have undergone significant

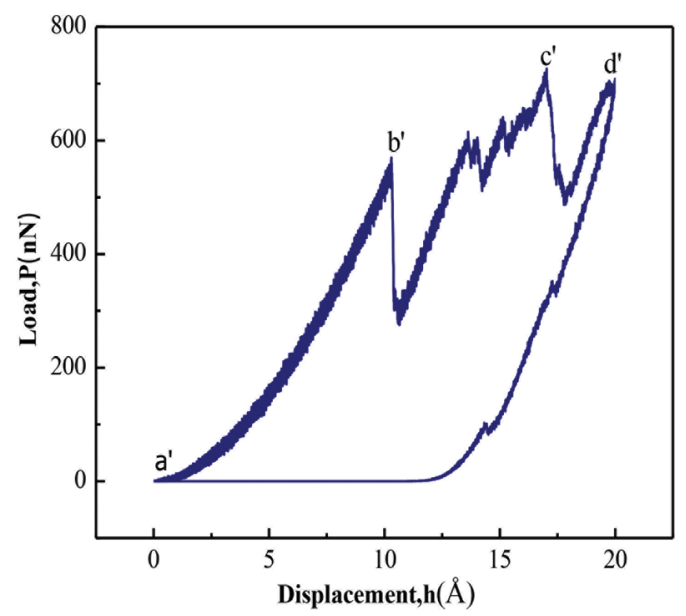

FIGURE 2. P-h curve for loading and unloading for the perfect model
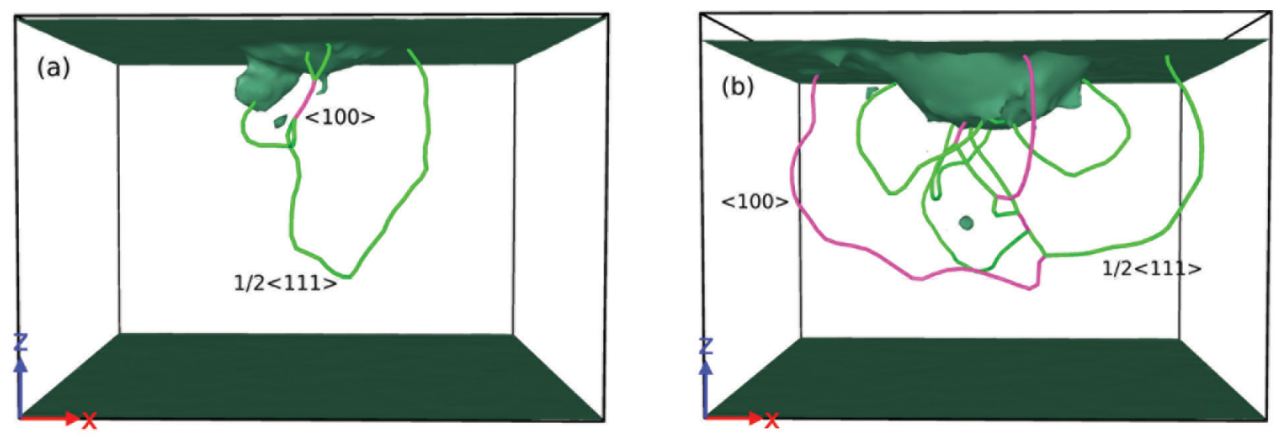

FIGURE 3. MD snapshot of deformation phases and dislocations nucleation for the perfect model at the indentation depth of (a) $17.5 \AA$. (b) $20 \AA$ 

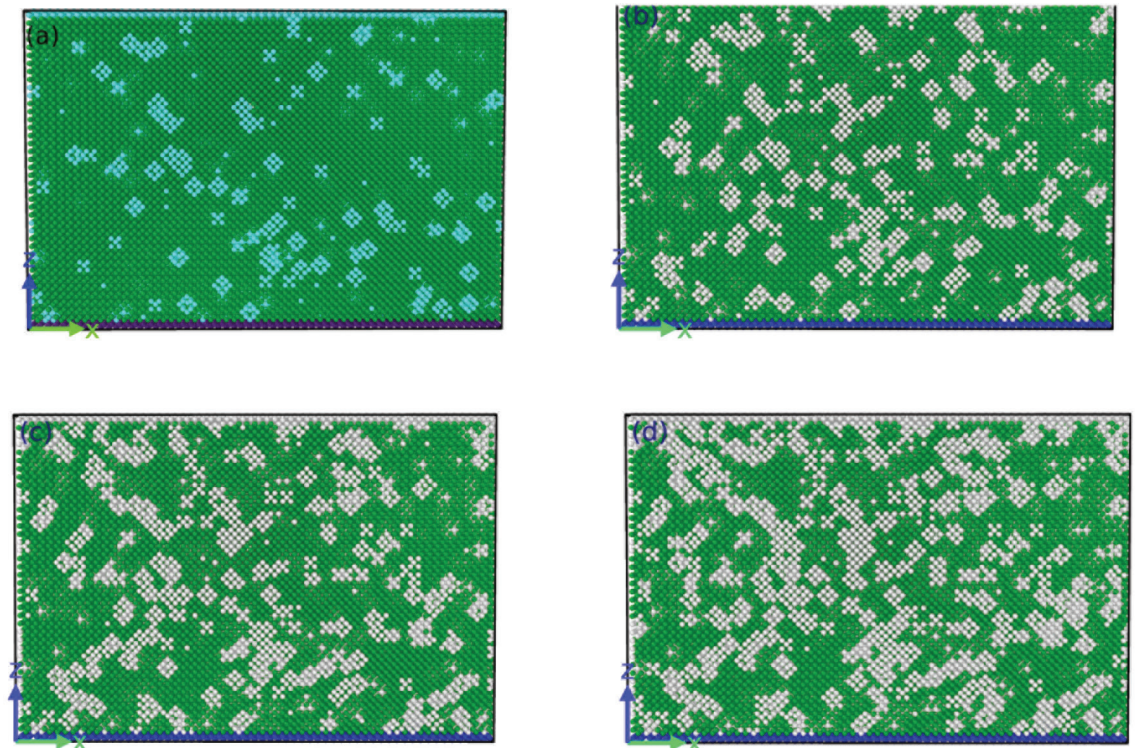

FIGURE 4. MD snapshot point defects model

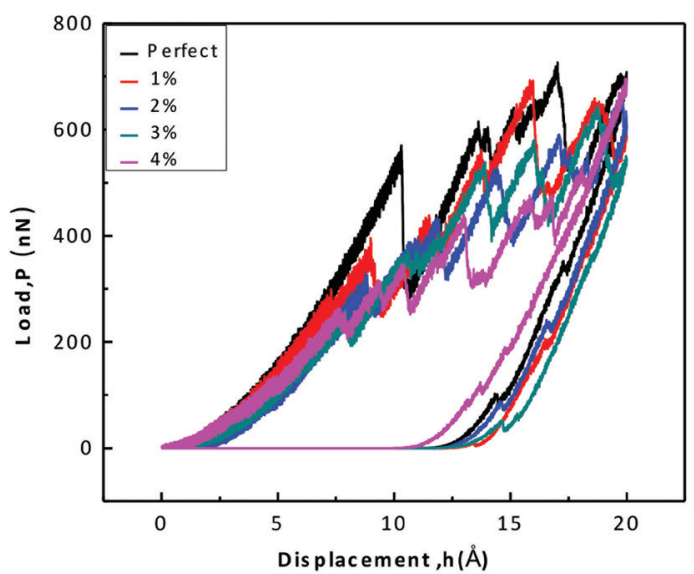

FIGURE 5. P-h curves for $1-4 \%$ points defect models

changes as reported by Tan and Jeng (2009). It can be seen from P-h curve in Figure 5 that random distribution of point defects provide more penetration depth and higher dislocation density, confirming the contribution of the defect to radiation hardening as reported by Nakai et al. (2016).

\section{VOIDS MODELS}

Voids model A Figure 6 shows the MD snapshot for $1 \%$ deleted voids model having different radii. Strictly speaking, the total number of deleted atoms cannot be exactly equal to $1 \%$ of the perfect model's atoms i.e. 2916 atoms because the number of deleted spherical regions can only be integers. This is one of the three basic conditions mentioned earlier. Therefore, taking $\mathrm{R}=2$, forty-six regions have been deleted which contain 2931 atoms. Therefore, an average of 64 atoms is deleted for each area. For $\mathrm{R}=3$, twelve regions are deleted with 3,151 atoms being deleted having an average of 251 deleted atoms per region.
Similarly, for $\mathrm{R}=4$, six regions are deleted that contain 3210 deleted atoms making an average of 535 deleted atoms for each region. A similar method can be opted for $2 \%$ deleted void model while keeping the other conditions same. In spherical region with $\mathrm{R}=2$, ninety-two regions have been deleted which contain 5828 atoms. Similarly, an average of 57 atoms are deleted per region for each area. For $\mathrm{R}=3$, twenty-three spherical regions are deleted which contain 5858 atoms. Therefore, an average of 254 atoms are deleted for each region. For radius 4 , eleven regions are deleted that contain 5892 deleted atoms. Therefore, an average of 535 atoms are deleted for each region (MD snapshot for $2 \%$ void model is not shown here).

Figure 7 represents comparative P-h curves for perfect and $1-2 \%$ voids models. In Figure 7 , it can be seen that P-h curves are shifted downwards along the abscissa since more dislocations are generated as compared to the perfect model. Similarly, we can see that the slopes of the point defect models are smaller than the perfect model. It can be analyzed that the indenter pressure on the void model 

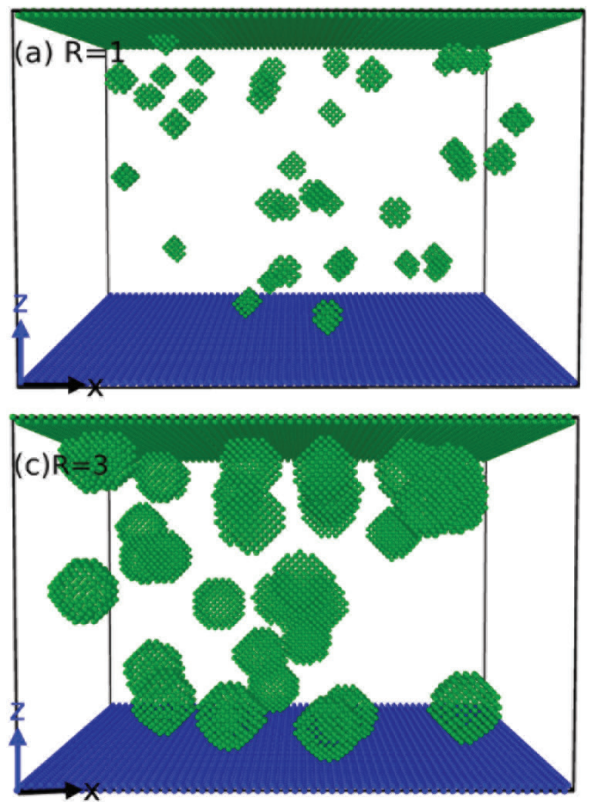
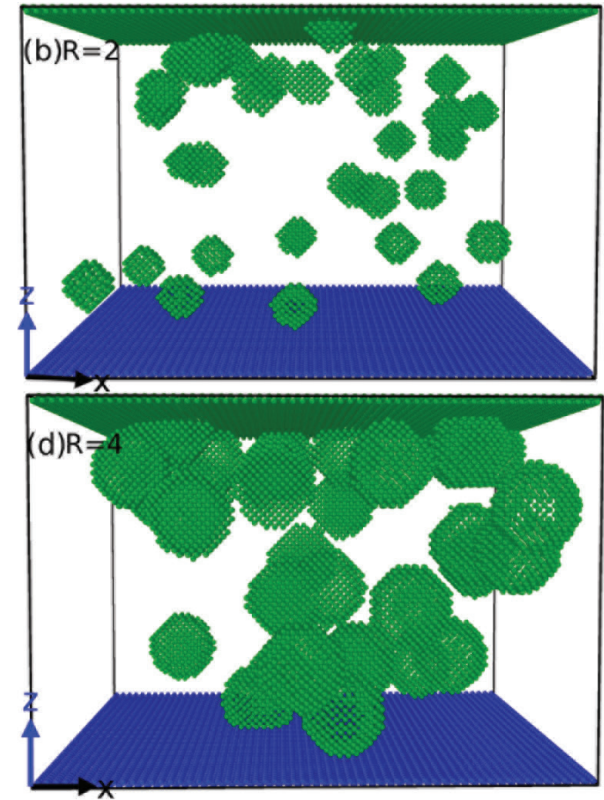

FIGURE 6. Voids model with different radii having $1 \%$ of the total atoms deleted, where $\left(\mathrm{R}=\mathrm{R}_{\mathrm{x} \text { lattice constant }}\right)$

is lower than that of the perfect model as reported by Abu-shams and Ishraq (2017).

Voids model $B$ To establish voids model B, we randomly selected 20 mutually independent spherical regions by changing radius of the spherical regions. The selection of all these regions satisfy the basic principles as mentioned earlier for model A. Nanoindentation simulation is performed with a lattice constant of radii 1, 2, 3, 4, respectively. Figure 8 shows deleted spherical areas having same positions but different radii. It is evident that locations of the deleted spherical areas and number of atoms are the same but the radii of voids is increasing.

The model in Figure 8(a), 290 atoms are removed with an average of 14 atoms per region. In Figure 8(b), 1281 atoms are removed with an average of 64 atoms for each region. In Figure 8(c), 5047 atoms are removed with an average of 252 atoms per region.

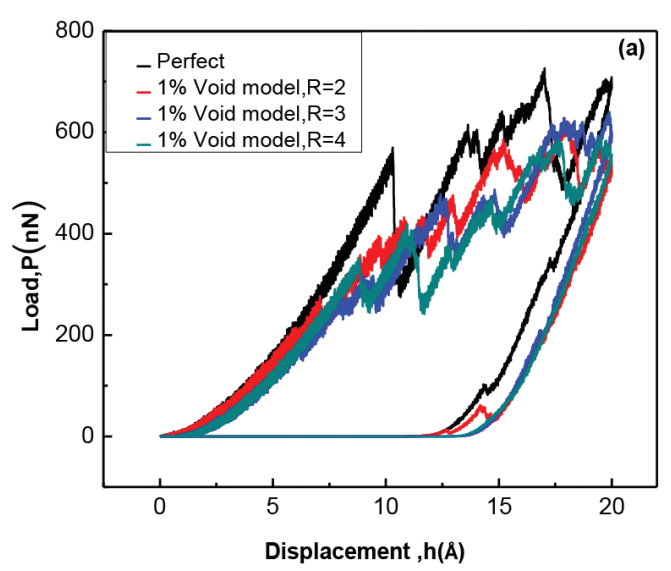

Figure 9 displays a comparative P-h curve for a spherical void model and perfect model. It can be seen that the Perfect model and void model of $\mathrm{R}=1$ overlap each other. It can be seen that shear modulus decreases drastically when sizes of voids increases due to larger number of dislocations in the elastic-plastic region (Zhang et al. 2018). Hence, it is concluded that the presence of voids softens the material allowing more indentation depth at a given load with an increase in the void size (Zinkle \& Was 2013).

\section{MECHANICAL PARAMETERS}

HARDNESS (H) AND REDUCED ELASTIC MODULUS ( $\mathrm{E}_{\mathrm{r}}$ )

In order to study the influence of irradiation defects on the mechanical properties of the model, relevant mechanical parameters in various models are calculated. The elastic-

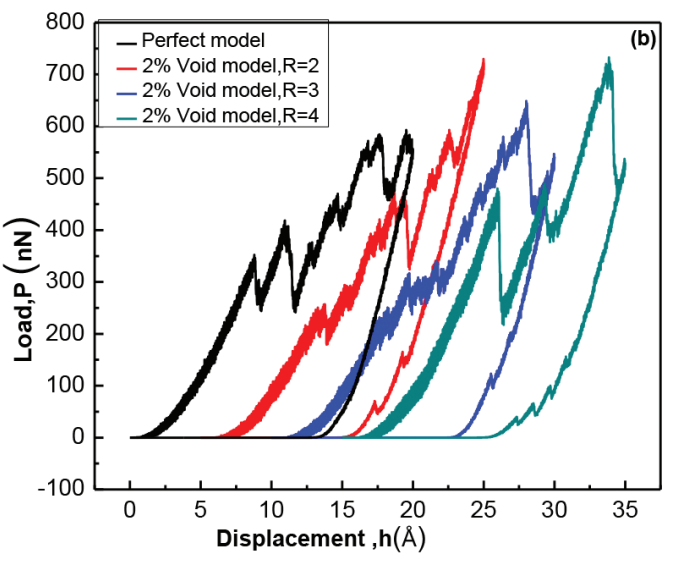

FIGURE 7. Comparative P-h curves for perfect and \% voids model (a) $1 \%$, (b) $2 \%$ 

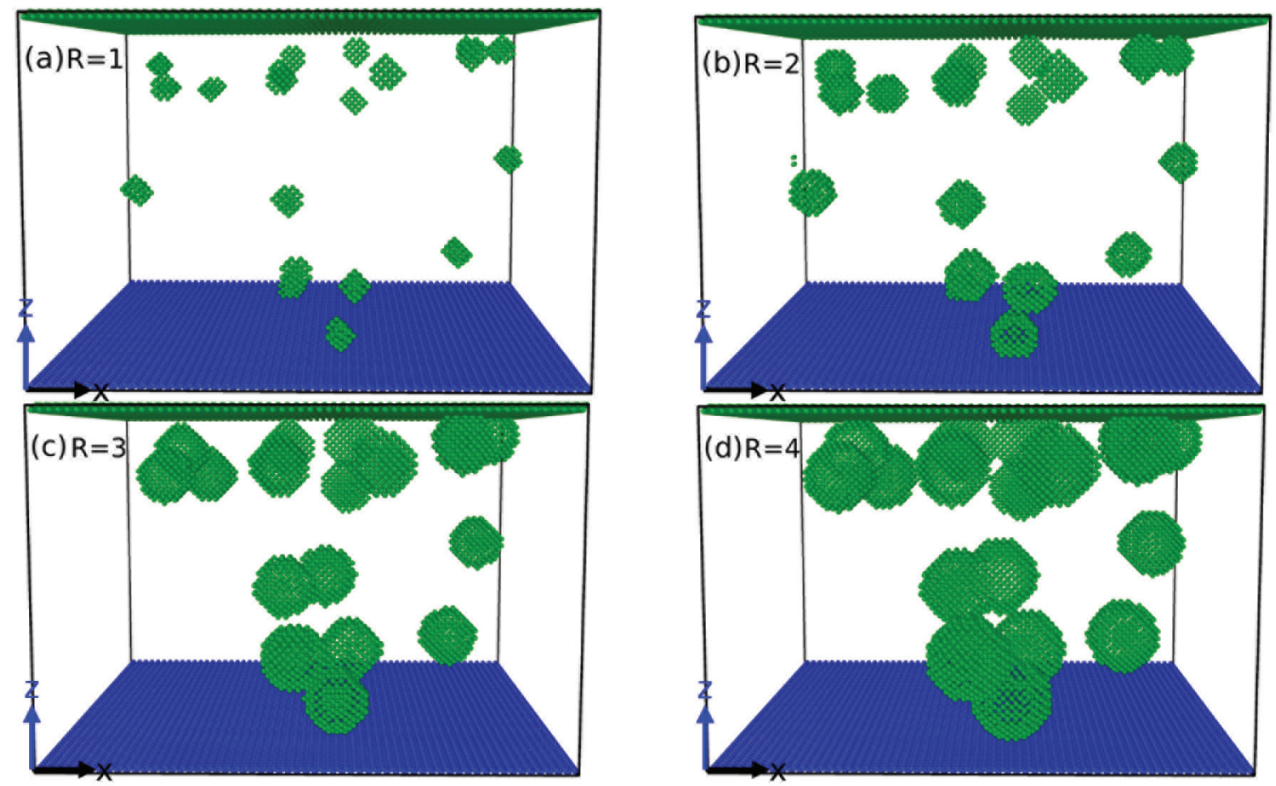

FIGURE 8. MD snapshot of voids model with same position with radii (a) $R=1$,

(b) $R=2$, (c) $R=3$, (d) $R=4$, where $\left(R=R_{x}\right.$ lattice constant $)$

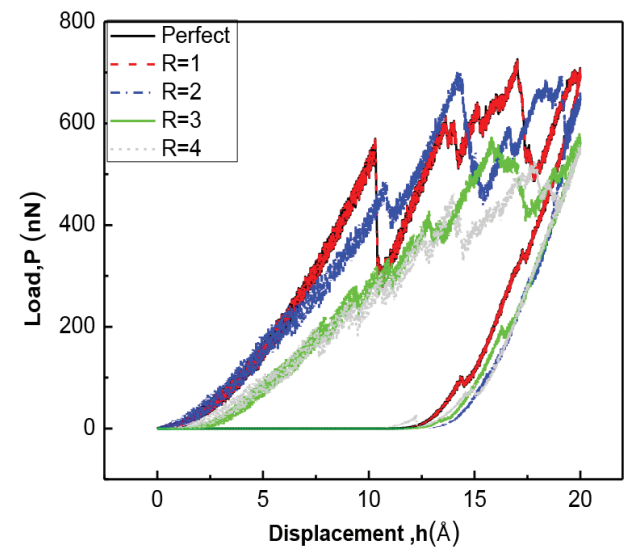

FIGURE 9. P-h curves with different radii when the void is fixed, where $(\mathrm{R}=\mathrm{R}$

plastic loading and elastic unloading part of P-h curve for each model can be used to calculate $\mathrm{H}$ while reduced modulus can be determined from the slope of the unloading part by Oliver and Pharr method (Pharr 1992).

$$
\begin{aligned}
& H=\frac{P}{A_{C}} \\
& E_{r}=\frac{1}{2 \beta} \sqrt{\frac{\pi}{A_{C}}} \frac{d P}{d h}
\end{aligned}
$$

where $\boldsymbol{A}_{C}$ is contact area; and $\boldsymbol{\beta}$ is constant for the shape of the indenter. For spherical indenters its value is 1.034 . Here, $\boldsymbol{P}$ is load, $\boldsymbol{E}_{r}$ is equivalent elastic modulus and $\frac{d P}{d h}$ (called stiffness) is the slope of the initial portion of unloading part of P-h curve. Equivalent elastic modulus is generally defined as;

$$
\frac{1}{E_{r}}=\frac{1-v_{1}^{2}}{E_{1}}+\frac{1-v_{2}^{2}}{E_{2}}
$$

where $\boldsymbol{E}_{1,2}, \boldsymbol{v}_{1,2}$ are elastic modulus, Poisson's ratio of sample and indenter, respectively. Since diamond indenter is considered for most of the experimental and simulation studies; therefore, mechanical parameters are calculated using the modulus of elasticity of the diamond indenter and the Poisson's ratio used as carried out by García Ferré et al. (2016).

For the simulation of single Fe crystal, $\boldsymbol{v}_{1}=0.27 \& \boldsymbol{E}_{1}=$ $211 \mathrm{GPa}$. For diamond indenters, $\boldsymbol{v}_{\mathbf{2}}=0.07 \& \boldsymbol{E}_{\mathbf{2}}=1141 \mathrm{GPa}$. 
Unloading part of the P-h curve is usually fitted using the following function,

$$
\mathbf{P}=\boldsymbol{\alpha}\left(\mathbf{h}-\mathbf{h}_{\mathrm{r}}\right)^{\mathbf{m}}
$$

and,

$$
S=\left(\frac{d P}{d \boldsymbol{h}}\right)_{h=h_{\max }}=\boldsymbol{\alpha} \boldsymbol{m}\left(\boldsymbol{h}_{\max }-\boldsymbol{h}_{r}\right)^{m-1}
$$

$\mathbf{h}_{r}$ is residual depth after unloading; $\boldsymbol{h}_{\text {max }}$ is maximum indentation depth; and $\boldsymbol{\alpha} \& \boldsymbol{m}$ are constants. To study the mechanical properties of each model, the slope of the unloading curve for each model was calculated. While hardness $\boldsymbol{H}$ and elastic modulus $\boldsymbol{E}_{r}$ of the models are calculated by using the mentioned relations. As the above physical parameters could be determined by the slope of the unloading curve $S$, the rest of the mechanical physical quantities can be obtained one by one for further analysis. Hence, it is recommended to initially calculate the slope of the unloading curve for each model. Then, calculate the hardness $\boldsymbol{H}$ and reduced elastic modulus $\boldsymbol{E}_{r}$ for all cases.

\section{ANALYSIS OF UNLOADING CURVES}

The slope of the unloading curve can be calculated using an appropriate range for fitting P-h curves. In order to fit the function at the maximum indenter's displacement, the initial process of unloading can be regarded as elastic deformation (Pharr 1992). Therefore, we choose different intervals in the unloading process for linear fitting and found out the mean value. The fitting models of unloading curves of 1-4\% points defect models and perfect model can be found from their corresponding slope by an appropriate section on the unloading curve. Therefore, we selected different ranges (i.e. 1,1 .5,2,2.5 $\AA$ ) for point defect models and $0.5 \sim 0.8 \AA$ for model B.

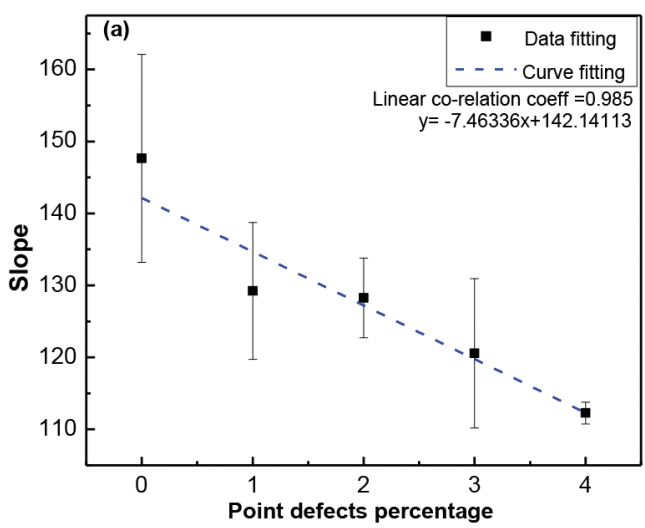

In Figure 10(a), it can be seen that slope and the percentage of deleted atoms are inversely proportional. The point corresponding to $0 \%$ is the slope of the perfect model which decreases linearly from $1 \%$ to $4 \%$. This result are in consonant with simulation performed by Zhan et al. (2011).

Figure 10(b) shows the variation of the slope with the radii of spherical voids of the unloading curve. It can be seen that the slope of unloading curve decreases exponentially as the radius increases. It is clear that the slope of the unloading curve of the model is reduced due to the existence of the voids in Fe. However, it can be qualitatively stated that the slope of the unloading curve of the model is reduced due to existence of the voids. Presence of voids can reduce stiffness $S$ under the indenter which can be used to interpret as elastic phase of the P-h curve (Tan \& Jeng 2009).

\section{CALCULATION FOR HARDNESS AND ELASTIC MODULUS POINT DEFECT MODELS}

The formula for solving the hardness and modulus of elasticity of the model is mentioned earlier. Previously obtained slopes, corresponding to the various models are used here. From Table 1, it can be seen that the hardness of the simulated point defect model is lower than that of the perfect model except that the $4 \%$ atomic model and was deleted. All models with simulated point defects have a lower modulus of elasticity than the perfect model. In Figure 11, the correlation coefficient fitted by exponential function is 0.89451 . As the number of deleted atoms keep on increasing, reduced elastic modulus is exponentially decreases whereas hardness is reduced by $7-8 \%$.

\section{VOIDS MODEL}

Using the slopes and correlations obtained earlier, we determined the mechanical parameters for model B as shown in Table 2.

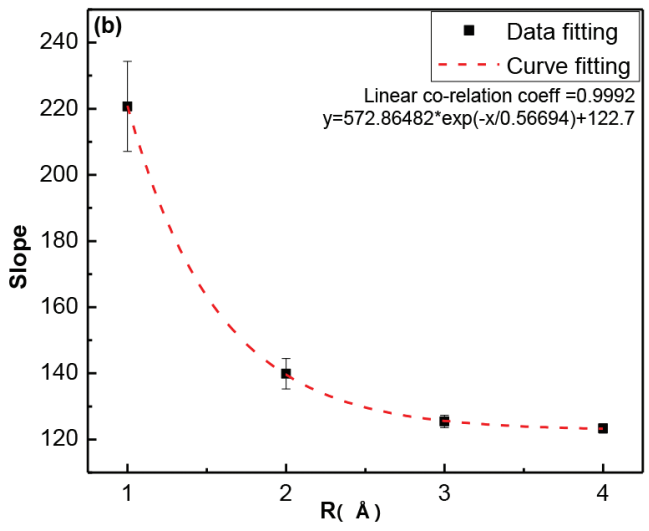

FIGURE 10. Variation of unloading curve slope with a) deleted atoms percentage

(b) Radii of spherical voids curve where $\left(\mathrm{R}=\mathrm{R}_{\mathrm{x} \text { lattice constant }}\right)$ 
TABLE 1. Mechanical parameters for point defects model

\begin{tabular}{cccccc}
\hline Quantity & $\mathrm{P}_{\max }$ & $\mathrm{h}_{\mathrm{c}}$ & $\mathrm{Ac}$ & $\mathrm{H}$ & $\mathrm{E}_{\mathrm{r}}$ \\
\hline Unit & $\mathrm{nN}$ & $\AA$ & $\mathrm{m}^{2} \times 10^{-20}$ & $\mathrm{GPA}$ & $\mathrm{GPA}$ \\
\hline Perfect model & 689.030 & 16.500 & 3596.937 & 19.156 & 239.747 \\
$1 \%$ model & 588.035 & 16.587 & 3402.382 & 17.283 & 203.600 \\
$2 \%$ model & 605.236 & 16.461 & 3590.370 & 16.857 & 202.467 \\
$3 \%$ model & 544.840 & 16.611 & 3615.291 & 15.070 & 187.429 \\
$4 \%$ model & 692.493 & 15.374 & 3405.832 & 20.333 & 178.538 \\
\hline
\end{tabular}
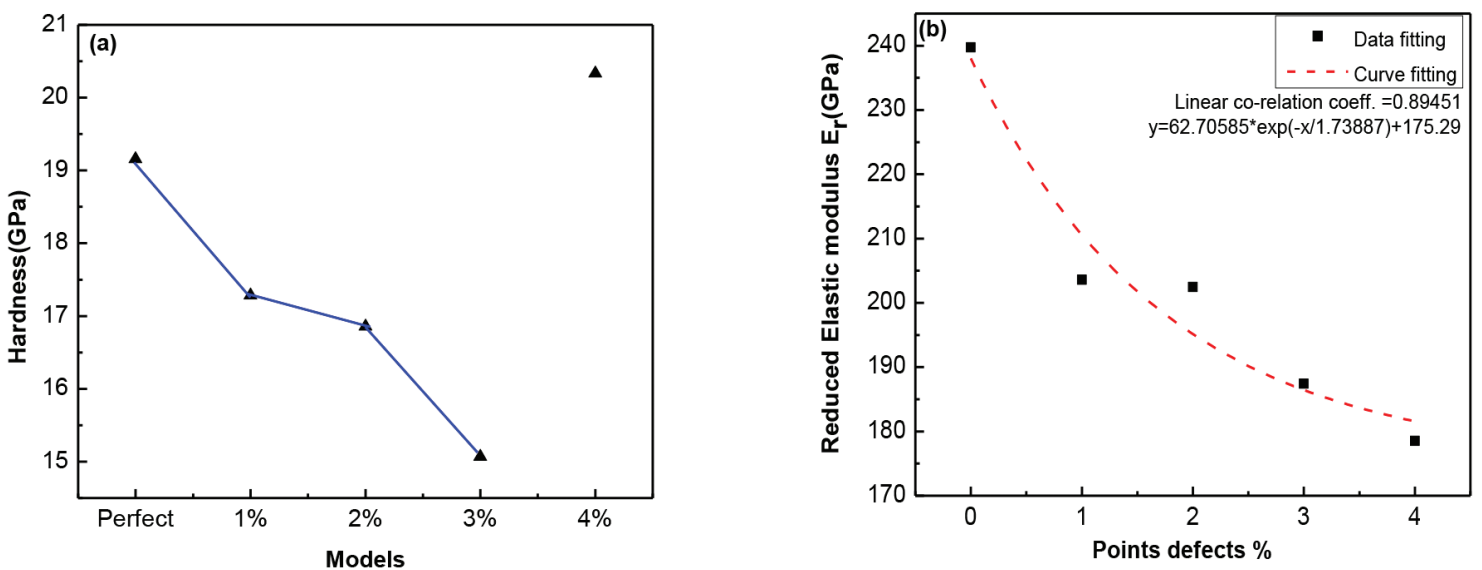

FIGURE 11. Variation of (a) Hardness (b) Reduced Elastic modulus with point defects

TABLE 2. Mechanical parameters of voids model $B$, where $\left(R=R_{x \text { lattice constant }}\right)$

\begin{tabular}{cccccc}
\hline Quantity & $\mathrm{P}_{\max }$ & $\mathrm{h}_{\mathrm{c}}$ & $\mathrm{A}_{\mathrm{c}}$ & $\mathrm{H}$ & $\mathrm{E}_{\mathrm{r}}$ \\
\hline Unit & $\mathrm{nN}$ & $\AA$ & $\mathrm{m}^{2} \times 10^{-20}$ & $\mathrm{GPA}$ & $\mathrm{GPA}$ \\
\hline Perfect model & 689.030 & 17.322 & 3731.417 & 18.466 & 328.651 \\
$\mathrm{R}=1$ & 701.396 & 17.617 & 3944.567 & 17.781 & 378.724 \\
$\mathrm{R}=2$ & 644.751 & 16.543 & 3760.039 & 17.147 & 218.553 \\
$\mathrm{R}=3$ & 558.870 & 16.659 & 3780.236 & 14.784 & 191.308 \\
$\mathrm{R}=4$ & 550.457 & 16.652 & 3779.096 & 14.566 & 187.522 \\
\hline
\end{tabular}

It can be seen from Table 2 that the reduced elastic modulus becomes smaller as the void size increases. Furthermore, the reduced elastic modulus and hardness are less than perfect model except for $\mathrm{R}=2$. In addition, the hardness of the model is reduced due to the presence of voids. For voids model A, no conclusion is drawn because of its irregularity, therefore, we have not tabulate it here. We have used average values for each case while calculating hardness and reduced elastic modulus. Hardness in each model is increased drastically in the initial phase due to generation of dislocations because the contact area of the indenter is less. With the increase in the indentation depth hardness becomes independent of its area. It is obvious that in defect-simulated models, hardness decreases as compared to the perfect model by a factor of 7-9\% and reduced elastic modulus exponentially decreases.
Figure 12 shows the variation of hardness and reduced elastic modulus for void model. It can be seen that both hardness and elastic modulus of the model decreases monotonically. In addition, fitting correlation coefficient is equal to 0.99997 which is close to 1 for 12(b).

\section{CONCLUSION}

In this study, we have performed MD simulation of nanoindentation response of irradiation defects on the mechanical properties of Fe. Three different types of models have been considered: Perfect, point defect and voids model. The P-h curve for each case has been analyzed in order to assess and calculate the mechanical parameters. Our results showed that P-h curve for each defect model is different from the perfect model. It has been concluded that hardness and elastic modulus of materials decreases 

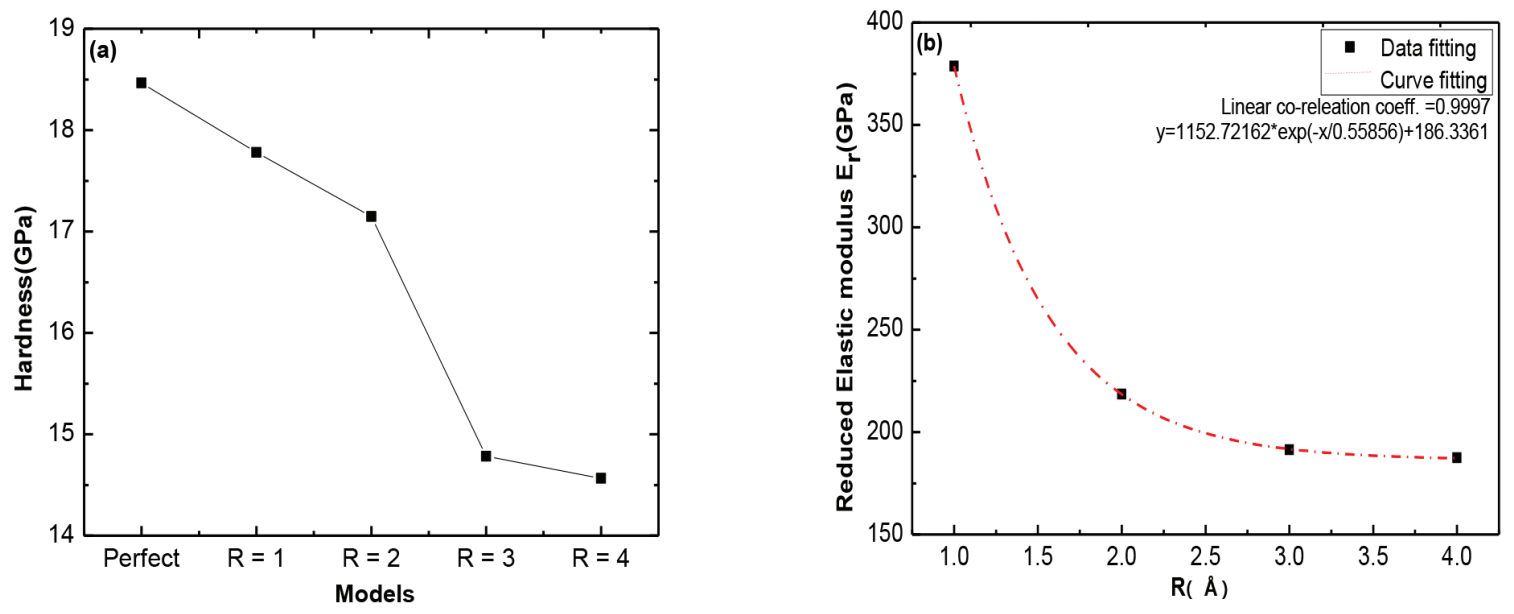

FIGURE 12. Variation of (a) Hardness with void radii (b) Elastic modulus with void radii

due to increase in point defects. The modulus of elasticity is decreased with point defects and trend is approximately exponential. For the voids case, we have analyzed two different situations. In both cases, hardness and elastic modulus of the material decreases exponentially with the increase in void. The hardness and modulus of elasticity of the models are less than the perfect model.

This work is quite valuable as we know that in any NPP environment, subject conditions do exist. But more importantly, these phenomena normally occur simultaneously in a practical plant. Therefore, their combined effect must also be analyzed. Hence, our future research will focus on utilizing extended multiscale simulation to study the combined effects of these individual models.

\section{ACKNOWLEDGEMENTS}

M Mustafa Azeem would like to extend gratitude to Chinese Scholarship Council (CSC) and College of Nuclear Science and Technology, Harbin Engineering University for their international scholarship program and immense academic support. Qingyu Wang acknowledges the support from the National Natural Science Foundation of China (grant no. 11505037) and the Fundamental Research Funds for Central Universities (grant no. HEUCFJ171502 and 3072019CF1502).

\section{REFERENCES}

Abu-shams Mohammad. \& Ishraq Shabib. 2017. Effect of voids on nanoindentation response of $\mathrm{Fe}-10 \% \mathrm{Cr}$ alloys using molecular dynamics simulation. Material Express 7(5): 329-340.

Ackland, G.J., Mendelev, M.I., Srolovitz, D.J., Han, S. \& Barashev, A.V. 2004. Development of an interatomic potential for phosphorus impurities in $\alpha$-Iron. Journal of Physics Condensed Matter 16(27). https://doi.org/10.1088/09538984/16/27/003.

Azevedo, C.R.F. 2011. Selection of fuel cladding material for nuclear fission reactors. Engineering Failure Analysis 18(8): 1943-1962.
Bacon, D.J. \& De Rubia, T.D. 1994. Molecular dynamics computer simulations of displacement cascades in metals. Journal of Nuclear Materials 216: 275-290.

Cheong, W.C.D. \& Zhang, L.C. 2006. Molecular dynamics simulation of phase transformations in silicon monocrystals due to nano-indentation. Nanotechnology 11(2000): 173-180.

Christopher, D., Smith, R. \& Richter, A. 2001. Atomistic modelling of nanoindentation in iron and silver. Nanotechnology 12(3): 372-383.

Dalmau, R., Franke, O., Biener, M., Biener, J., Hodge, A. \& Alcala, J. 2012. Planar defect nucleation and annihilation mechanisms in nanocontact plasticity of metal surfaces. Physical Review Letters 075502(8): 17-21.

Du, X., Zhao, H., Zhang, L., Yang, Y., Xu, H., Fu, H. \& Li, L. 2015. Molecular dynamics investigations of mechanical behaviours in monocrystalline silicon due to nanoindentation at cryogenic temperatures and room temperature. Scientific Reports 5(10): 16275.

García Ferré, F., Mairov, A., Ceseracciu, L., Serruys, Y., Trocellier, P., Baumier, C., Kaïtasov, O., Brescia, R., Gastaldi, D., Vena, P., Beghi, M.G., Beck, L., Sridharan, K. \& Di Fonzo, F. 2016. Radiation endurance in $\mathrm{Al} 2 \mathrm{O} 3$ nanoceramics. Scientific Reports 6(8): 33478.

Kilymis, D.A., Delaye, J.M. \& Ispas, S. 2016. Nanoindentation of the pristine and irradiated forms of a sodium borosilicate glass: Insights from molecular dynamics simulations. Journal of Chemical Physics 145(4): 044505.

Kohnert, A.A., Wirth, B.D. \& Capolungo, L. 2018. Modeling microstructural evolution in irradiated materials with cluster dynamics methods: A Review. Computational Materials Science 149: 442-459.

Lee, Y., Park, J.Y., Kim, S.Y., Jun, S. \& Im, S. 2005. Atomistic simulations of incipient plasticity under $\mathrm{Al}(111)$ nanoindentation. Mechanics of Materials 37: 1035-1048.

Liu, X., Miao, Y., Li, M., Kirk, M.A., Maloy, S.A. \& Stubbins, J.F. 2017. Ion-irradiation-induced microstructural Modi Fi cations in ferritic/martensitic steel T91. Journal of Nuclear Materials 490: 305-316.

Eldrup, M. \& Singh, B.N. 2013. Cavity nucleation and growth during helium implantation and neutron irradiation of fe and steel cavity nucleation and growth during helium implantation and neutron irradiation of $\mathrm{Fe}$ and steel. Journal of Physics Conference Series 443: 012023. 
Mazaheri Yousef, Ahmad Kermanpur. \& Abbas Najafizadeh. 2015. Nanoindentation study of ferrite-martensite dual phase steels developed by a new thermomechanical processing. Materials Science and Engineering A 639: 8-14.

Nakai Ryosuke, Kiyohiro Yabuuchi, Shuhei Nogami. \& Akira Hasegawa. 2016. The effect of voids on the hardening of body-centered cubic Fe. Journal of Nuclear Materials 471: 233-238.

Nordlund, K., Zinkle, S.J., Sand, A.E., Granberg, F., Averback, R.S., Stoller, R.E., Suzudo, T., Malerba, L., Banhart, F., Weber, W.J., Willaime, F., Dudarev, S.L. \& Simeone, D. 2018. Primary radiation damage: A review of current understanding and models. Journal of Nuclear Materials 512: 450-479.

Pharr, G.M. 1992. An improved technique for determining hardness and elastic modulus using load and displacement sensing indentation experiments. Journal of Materials Research 7(6): 1564-1583.

Plimpton, S. 1995. Fast parallel algorithms for short-range molecular dynamics. Journal of Computational Physics 117(1994): 1-19. https://doi.org/10.1006/jcph.1995.1039.

Renault, A., Gavoille, P., Malaplate, J., Pokor, C. \& Tanguy, B. 2015. Correlation of radiation-induced changes in microstructure/microchemistry, density and thermo-electric power of Type 304L and 316 stainless steels irradiated in the phénix reactor. Journal of Nuclear Materials 460: 72-81.

Richter, A., Gheewala Ismail, Smith, R., Kenny, S.D., Valdez, J. $\&$ Sickafus, K. 2008. Changes in the mechanical properties of irradiated $\mathrm{MgO}(100)$ crystals investigated by nanoindentation and computer simulation. Journal of Nuclear Materials 382(2-3): 176-183.

Rofman, O.V., Maksimkin, O.P., Tsay, K.V., Koyanbayev, Y.T. \& Short, M.P. 2017. The natural aging of austenitic stainless steels irradiated with fast neutrons the natural aging of austenitic stainless steels irradiated with fast neutrons. Journal of Nuclear Materials 499(November): 284-293.

Ruestes, C.J. 2017. Atomistic studies of nanoindentation-A review of recent advances. Crystals 7(10): 293.

Shan, L.D.B., Yuan, L., Xu, Z.H. \& Guo, B. 2009. Atomistic simulation of voids effect on nanoindentation. Journal of Nanoscience and Nanotechnology 9(2): 1234-1236.

Stukowski, A. 2010. Visualization and analysis of atomistic simulation data with OVITO-the open visualization tool. Modelling and Simulation in Materials Science and Engineering 18(1): 15012.

Tan, C.M. \& Jeng, Y.R. 2009. Computer simulations of nanoindentation on $\mathrm{Cu}$ (111) with a void. International Journal of Solids and Structures 46(9): 1884-1889.

Tan, L., Katoh, Y., Tavassoli, A.F., Henry, J., Rieth, M., Sakasegawa, H., Tanigawa, H. \& Huang, Q. 2016. Recent status and improvement of reduced-activation ferriticmartensitic steels for high-temperature service. Journal of Nuclear Materials 479: 515-523.

Terentyev, D., Bonny, G., Domain, C., Monnet, G. \& Malerba, L. 2013. Mechanisms of radiation strengthening in $\mathrm{Fe}-\mathrm{Cr}$ alloys as revealed by atomistic studies. Journal of Nuclear Materials 442(1-3): 470-485.
Tschopp, M.A., Gao, F., Yang, L. \& Solanki, K.N. 2014. Binding energetics of substitutional and interstitial helium and $\mathrm{Di}$ helium defects with grain boundary structure in $\alpha$-Fe. Journal of Applied Physics 115(3): 033503.

Tschopp, M.A., Horstemeyer, M.F., Gao, F., Sun, X. \& Khaleel, M. 2011. Energetic driving force for preferential binding of self-interstitial atoms to $\mathrm{Fe}$ grain boundaries over vacancies. Scripta Materialia 64(9): 908-911.

Uberuaga, B.P., Martínez, E., Perez, D. \& Voter, A.F. 2018 Discovering mechanisms relevant for radiation damage evolution. Computational Materials Science 147: 282-292.

Voyiadjis, G.Z. \& Mohammadreza Yaghoobi. 2015. Large scale atomistic simulation of size effects during nanoindentation: Dislocation length and hardness. Materials Science and Engineering A 634: 20-31.

Was, G.S. 2007. Fundamentals of Radiation Materials Science: Metals and Alloys. Berlin: Springer-Verlag.

Wolfer, W.G. 2012. Fundamental properties of defects in metals. In Comprehensive Nuclear Materials. https://doi. org/10.1016/B978-0-08-056033-5.00001-X.

Yabuuchi, K., Kasada, R. \& Kimura, A. 2013. Effect of alloying elements on irradiation hardening behavior and microstructure evolution in BCC Fe. Journal of Nuclear Materials 442(1-3): 790-795.

Yvon, P. \& Carré, F. 2009. Structural materials challenges for advanced reactor systems. Journal of Nuclear Materials 385(2): 217-222.

Zhan, H.F., Gu, Y.T. \& Yarlagadda, P.K.D.V. 2011. Advanced numerical characterization of mono- crystalline copper with defects. Advanced Science Letters 4(5): 1293-1301.

Zhang, X., Hattar, K., Chen, Y., Shao, L., Li, J., Sun, C., Yu, K., Nan, L., Mitra, T., Wang, H., Wang, J. \& Michael, N. 2018. Radiation damage in nanostructured materials. Progress in Materials Science 96: 217-321.

Zinkle, S.J. \& Was, G.S. 2013. Materials challenges in nuclear energy. Acta Materialia 61(3): 735-758.

M. Mustafa Azeem \& Qingyu Wang*

College of Nuclear Science and Technology

Harbin Engineering University

Harbin 150001

China

Muhammad Zubair

Department of Nuclear Engineering

University of Sharjah

United Arab Emirates

*Corresponding author; email: wangqingyu@ @rbeu.edu.cn

Received: 25 February 2019

Accepted: 12 July 2019 